\title{
Efficacy and Safety of Low-Dose Prasugrel Versus Clopidogrel in Patients With Acute Coronary Syndrome or Patients Undergoing Percutaneous Coronary Intervention: A Systematic Review and Meta-Analysis
}

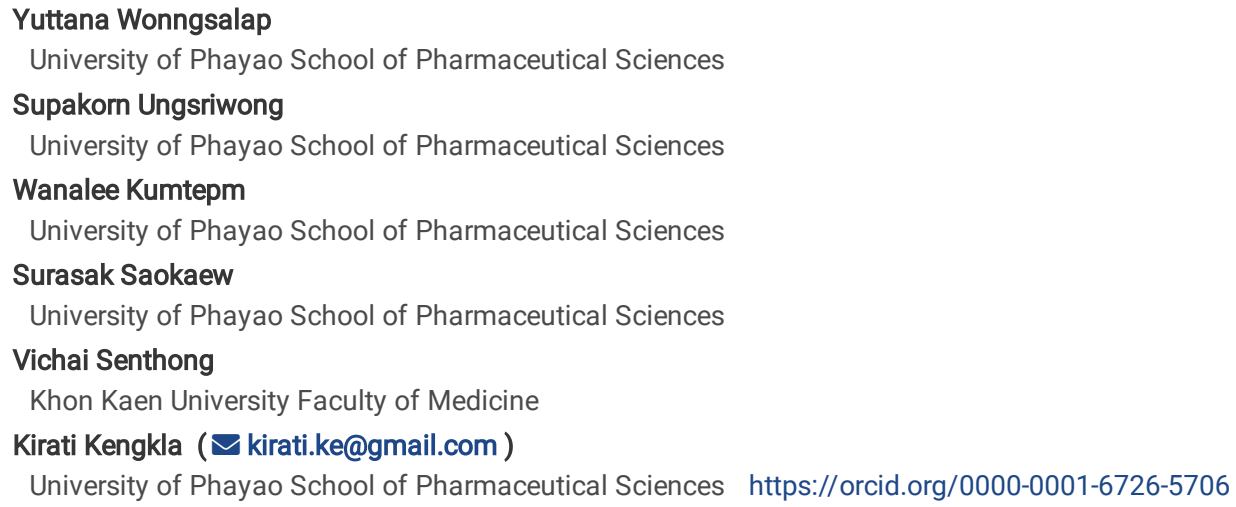




\section{Abstract \\ Purpose}

To assess the efficacy and safety of prasugrel at low doses compared to clopidogrel by looking at the occurrence of major adverse cardiac events (MACE) and major bleeding in patients with acute coronary syndrome (ACS) or undergoing percutaneous coronary intervention ( $\mathrm{PCl})$.

\section{Methods}

We searched PubMed, EMBASE, the Cochrane Central Register of Controlled Trials, and ClinicalTrials.gov for eligible randomized controlled trials (RCTs) and observational studies assessing efficacy and safety of low-dose prasugrel versus clopidogrel in patients with ACS or undergoing PCI up to May 22, 2020. We did a meta-analysis using a random-effects model to estimate relative risks (RRs). The primary efficacy and safety endpoints were MACE and major bleeding, respectively.

\section{Results}

Six RCTs $(n=6,131)$ and six observational studies $(n=31,426)$ were included. There was no MACE reduction in patients receiving low-dose prasugrel compared with those receiving clopidogrel ( $R R 1.02,95 \% \mathrm{Cl} 0.91$ to 1.14 ), but there was an increased risk of major bleeding (RR $1.35,95 \% \mathrm{Cl} 1.10$ to 1.67$)$.

\section{Conclusions}

Low-dose prasugrel yields no increase in efficacy when compared with clopidogrel, but it does expose patients to an increased risk of bleeding. Most studies considered here were conducted in Japan. Studies conducted with non-Asian patients may find that low-dose prasugrel offers a more favorable efficacy and risk profile. Considering the results of this analysis we believe low-dose prasugrel should be prescribed with extreme caution as it may result in bleeding events without any additional benefit over clopidogrel.

\section{Introduction}

Dual antiplatelet therapy (DAPT) combining aspirin and a P2Y12 inhibitor has become an essential part of acute coronary syndrome (ACS) treatment, particularly for patients undergoing percutaneous coronary intervention (PCI) [1, 2]. The use of DAPT reduces the risk of major ischemic events. [2, 3]. Clopidogrel has been a widely used P2Y12 inhibitor used in DAPT, but slow onset of action, variability in patient responses, and problems with drug resistance have led to pressure to develop new P2Y12 inhibitors [4, 5].

Prasugrel is a third-generation thienopyridine antiplatelet drug that provides more rapid onset and greater inhibition of platelet function than clopidogrel [6]. Because of these advantages, the new ESC clinical practice guidelines for the management of ACS in patients presenting without persistent ST elevation recommend prasugrel as a preferred P2Y12 inhibitors in ACS patients undergoing PCI [3]. The standard dose of prasugrel has been shown to reduce the risk of ischemic events, including stent thrombosis compared with clopidogrel in patients with ACS undergoing PCI [7]. However, in some instances prasugrel may be too effective at inhibiting platelet function, and patients receiving the drug have exhibited severe and even fatal bleeding. Indeed, no net clinical benefit was observed in elderly patients ( $\geq 75$ years of age), patients with low body weight $<60 \mathrm{~kg}$ [7], or in patients of Asian origin due to the increased risk of bleeding in these populations $[8,9]$. Hence, protocols for the use of prasugrel have rapidly adopted lower recommended doses for patients with ACS, particularly in East Asian populations to mitigate bleeding risk.

Previous randomized controlled trials (RCTs) have demonstrated that low-dose prasugrel has a similar efficacy and safety profile to clopidogrel. In the TRILOGY-ACS study, reduced-dose prasugrel (loading dose of $60 \mathrm{mg}$ and maintenance dose of $5 \mathrm{mg}$ ) was associated with a similar risk of ischemic events and bleeding events compared with clopidogrel in an elderly population with ACS [10]. In the PRASFIT-ACS study, an even lower dose of prasugrel (loading dose of $20 \mathrm{mg}$ and maintenance dose of $3.75 \mathrm{mg}$ ) provided similar efficacy without an increased risk of bleeding compared with clopidogrel, suggesting that risks and benefits of the drug can be effectively balanced in an East Asian population [11]. However, large observational studies in Japan found that low-dose prasugrel was associated with a significantly increased risk of short-term bleeding, and patients in these studies did not exhibit any beneficial reduction in ischemic events. In fact, patients treated with low-dose prasugrel trended towards having more ischemic events than those treated with clopidogrel [12, 13]. It is not clear why these studies have found conflicting results, and it remains a major issue to understand the relationship between the risks and benefits of prasugrel at low doses.

Honing protocols used for prasugrel administration is now a pressing issue as this drug is likely to be used widely because of its status as a preferred P2Y12 inhibitors [3]. To address this issue, we performed a systematic review and meta-analysis to assess the risks and benefits of prasugrel at low doses compared to clopidogrel by looking at the occurrence of major bleeding and major adverse cardiac events (MACE) in patients with ACS or undergoing PCl.

\section{Methods}

This study was done in accordance with the Preferred Reporting Items for Systematic Reviews and Meta-Analyses (PRISMA) guidelines for meta-analyses of interventional studies [14], and observational studies [15]. The study protocol was registered on PROSPERO (CRD42020188261) [16]. 


\section{Participants and interventions}

Our systematic review focused on patients with ACS or patients who undergoing PCl. The intervention of interest was low-dose prasugrel (60/5 mg loading/maintenance dose or 20/3.75 mg loading/maintenance dose) for long-term therapy.

\section{Search strategy and study selection criteria}

We search PubMed, EMBASE, the Cochrane Central Register of Controlled Trials, and ClinicalTrial.gov from inception until May 22, 2020. Our search terms were: ("myocardial infarction" OR "coronary artery disease" OR "coronary heart disease" OR "ischemic heart disease") AND prasugrel AND ("cardiac event" OR cardiovascular event* OR cerebrovascular event* OR stent thrombosis OR mortality OR death OR bleeding). We applied no language, publication date, and publication status restrictions. We also hand-searched the bibliographies of included studies and relevant systematic review articles for additional articles. The inclusion criteria were: (1) RCTs or observational studies enrolling patients with ACS or patients who undergoing PCl; (2) comparison of low-dose prasugrel versus standard-dose clopidogrel (300-600/75 mg, loading/maintenance dose); (3) reporting of MACE, death, cardiovascular death, stroke, myocardial infarction (MI), and major or minor bleeding during follow-up. Studies were excluded for any of the following: (1) abstract without full-text or conference proceeding; (2) studies with insufficient data to calculate or extract effect estimates; (3) studies only reporting pharmacodynamic parameters without considering the cardiac endpoints or bleeding. Further details of search strategies are provided in Table S1.

\section{Study selection and data extraction}

Records were independently screened by title and abstracts to identify potential studies according to the inclusion/exclusion criteria by three investigators (YW, SU or WK). Disagreements were resolved by discussion or a fourth reviewer (KK). Each potentially relevant study was reviewed in full by the same investigators. Data were extracted by two investigators (any two of YW, SU or WK) using standard data extraction forms. The number of events in intention to treat analysis was collected. Adjusted effect estimates (hazard ratio [HR], risk ratio [RR], or odds ratio [OR]) with 95\% confidence interval were extracted from observational studies. Any disagreement was resolved by discussion with another reviewer (SS).

\section{Outcomes}

The primary efficacy outcome was MACE, defined as the composite of death, non-fatal MI, or non-fatal stroke. The primary safety outcome was major bleeding based on Thrombolysis in Myocardial Infarction (TIMI) criteria [17] or Bleeding Academic Research Consortium (BARC) criteria type 3 or 5 [18]. The secondary endpoint was minor bleeding based on TIMI criteria; and type 1 or 2 bleeding based on BARC criteria [17, 18]. We also evaluated individual components of MACE outcome, and stent thrombosis as additional outcomes. The precise definition of cardiovascular death, non-fatal Ml, stent thrombosis, and stroke were determined separately by each study. No substantive differences were apparent in these definitions.

\section{Quality assessment}

Two investigators (YW, KK) independently appraised the quality of included studies using Cochrane Risk of Bias Tools as appropriate to each study's design. RCTs were assessed according to the revised Cochrane Risk of Bias Tool for Randomized Trials (RoB version 2.0) [19]. This method considers the study's randomization process, bias due to deviations from intended interventions, missing outcome data, measurement of the outcome, and selection of the reported result. Each domain was qualitatively classified as at high, medium, or low risk of bias. We used the Risk Of Bias In Non-randomized Studies of Interventions (The ROBINS-I) tool to evaluate the risk of bias in observational studies. This method considers confounding factors, selection of participants, classification of intervention, deviations from intervention, missing data, measurement of outcome and selection of reported results. Each domain was qualitatively classified as at critical, serious, moderate, or low risk of bias. Risk of bias graphs was derived from these tools [20].

\section{Data management and analysis}

We conducted separate analyses for randomized controlled trials and observational studies. We estimated the risk ratios (RRs) with $95 \%$ confidence interval (Cl) for dichotomous outcomes. Heterogeneity was assessed using the Cochrane Q-statistic and quantified using $\mathrm{I}^{2}$ test with scores below $50 \%$ deemed low, $50 \%-75 \%$ deemed moderate and $>75 \%$ deemed high heterogeneity [21]. Because we assumed treatment effects varied across trials, we used a random effects model (the DerSimonian and Laird method) to calculate the pooled RRs and 95\% Cis [22, 23]. To combine data from observational studies, we obtained adjusted values for log [risk ratio] and log [standard error]. HR and OR were converted to RRs [24]. We assessed small-study effects by using Egger's test with the finding of a visually asymmetrical funnel plot indicating the existence of bias [25]. We performed subgroup analyses based on clinical characteristics (e.g., dose of prasugrel ( $3.75 \mathrm{mg}$ or $5 \mathrm{mg}$ ), types of clinical events, types of $\mathrm{PCl}$, age groups, and study country). Interactions between subgroups were examined with a test for heterogeneity with alpha set to 0.05 . Sensitivity analyses were performed by excluding studies with a high risk of bias to assess the robustness of the findings. Statistical testing was two-sided with alpha set at 0.05 .

We used the Grading of Recommendations, Assessment and Evaluation (GRADE) framework to report the overall quality of evidence. The certainty in the evidence for each outcome was graded as high, moderate, low, or very low [26, 27].

\section{Results}

Study selection

Overall, 5396 records were identified through database searching. 125 additional records were identified through other sources. After removal of duplicates, a total of 4406 records remained and were initially screened by title and abstract. Of these, 40 were included for full-text review. Twelve studies were included in the final analysis consisting of six RCTs [10, 11, 28-31] and six observational studies [12, 13, 32-35]. The study selection is illustrated in Fig. 1.

Study characteristics 
The characteristics of the included studies are summarized in Table 1. Overall, these 12 studies involved 37,557 patients. Six were RCTs (6,131 patients), while the other 6 were observational studies (31,426 patients). The mean age of study participants was 69.9 years (Standard deviation [SD], 5.1) and 24.3\% of participants were female (interquartile range [IQR], 19.6\% - 33.8\%). Eight studies (66.7\%) were performed with ACS patients [10-13, 31, 30, 33, 35], and four studies (33.3\%) were performed with CAD patients [28, 29, 32, 34]. Nine studies (75.0\%) examined the effects of a $3.75 \mathrm{mg}$ dose of prasugrel [10, $12,13,28$, $31-35]$, two studies $(16.7 \%)$ examined $5 \mathrm{mg}$ dose [11,30] and one (8.3\%) compared these two doses [29]. Most studies were conducted in Japan (10 studies) [11-13, 28-30, 32-35], while the other 2 studies included one conducted in Italy [31] and one that gathered data from 52 countries around the world [10]. The median duration of follow-up was 12 months (IQR, 8-12 months). Characteristics of all included studies are given in Table S2.

Table 1

Study characteristics of included studies

\begin{tabular}{|c|c|c|c|c|c|c|c|c|c|c|c|}
\hline \multirow[t]{2}{*}{ Study } & \multirow{2}{*}{$\begin{array}{l}\text { Study } \\
\text { design }\end{array}$} & \multirow[t]{2}{*}{ Country } & \multirow{2}{*}{$\begin{array}{l}\text { Target } \\
\text { population }\end{array}$} & \multirow{2}{*}{$\begin{array}{l}\text { Total } \\
\text { population }\end{array}$} & \multirow[t]{2}{*}{ Patients } & \multirow{2}{*}{$\begin{array}{l}\text { Intervention } \\
\text { (n) }\end{array}$} & \multirow[t]{2}{*}{ Control (n) } & \multicolumn{2}{|c|}{ Outcomes } & \multirow{2}{*}{$\begin{array}{l}\text { Follow- } \\
\text { up } \\
\text { (months) }\end{array}$} & \multirow{2}{*}{$\begin{array}{l}\mathrm{Ag} \\
\text { (ye } \\
\mathrm{Me}\end{array}$} \\
\hline & & & & & & & & MACE & $\begin{array}{l}\text { Major } \\
\text { Bleeding }\end{array}$ & & \\
\hline $\begin{array}{l}\text { Isshiki } \\
(2014) \\
{[28]}\end{array}$ & RCT & Japan & $\begin{array}{l}\text { Asian } \\
\text { (Japanese } \\
\text { patients) }\end{array}$ & 742 & $\begin{array}{l}\mathrm{CAD} \text { (stable angina } \\
\text { or prior } \mathrm{MI} \text { ) } \\
\text { undergoing } \mathrm{PCl}\end{array}$ & $\begin{array}{l}\text { prasugrel } \\
20 / 3.75 \mathrm{mg} \\
(370)\end{array}$ & $\begin{array}{l}\text { clopidogrel } \\
300 / 75 \\
\mathrm{mg}(372)\end{array}$ & Yes & Yes & 12 & 27. \\
\hline $\begin{array}{l}\text { Kimura } \\
\text { (2015) } \\
{[29]}\end{array}$ & RCT & Japan & $\begin{array}{l}\text { Asian } \\
\text { (Japanese } \\
\text { patients) }\end{array}$ & 422 & $\begin{array}{l}\mathrm{CAD} \text { (stable angina } \\
\text { or prior } \mathrm{MI} \text { ) } \\
\text { undergoing } \mathrm{PCl}\end{array}$ & $\begin{array}{l}\text { prasugrel } \\
20 / 3.75-5 \\
\mathrm{mg}(207)\end{array}$ & $\begin{array}{l}\text { clopidogrel } \\
300 / 75 \\
\mathrm{mg}(104)\end{array}$ & Yes & Yes & 3.5 & 14. \\
\hline $\begin{array}{l}\text { Roe } \\
\text { (2013) } \\
{[10]}\end{array}$ & RCT & Italy & $\begin{array}{l}\text { Elderly } \\
\text { patients } \\
\text { (age } \geq 75 \\
\text { years) }\end{array}$ & 2083 & ACS (UA/NSTEMI) & $\begin{array}{l}\text { prasugrel } \\
\text { NA/5 mg } \\
(1043)\end{array}$ & $\begin{array}{l}\text { clopidogrel } \\
\text { NA/75 mg } \\
(1040)\end{array}$ & Yes & Yes & 30 & 50. \\
\hline $\begin{array}{l}\text { Saito } \\
\text { (2014) } \\
{[11]}\end{array}$ & RCT & Japan & $\begin{array}{l}\text { Asian } \\
\text { (Japanese } \\
\text { patients) }\end{array}$ & 1363 & $\begin{array}{l}\text { ACS } \\
\text { (UA/STEMI/NSTEMI) } \\
\text { undergoing PCl }\end{array}$ & $\begin{array}{l}\text { prasugrel } \\
20 / 3.75 \mathrm{mg} \\
(685)\end{array}$ & $\begin{array}{l}\text { clopidogrel } \\
300 / 75 \\
\mathrm{mg}(678)\end{array}$ & Yes & Yes & 12 & 21. \\
\hline $\begin{array}{l}\text { Savonitto } \\
(2018) \\
{[31]}\end{array}$ & RCT & $\begin{array}{l}52 \\
\text { countries } \\
\text { around } \\
\text { the world }\end{array}$ & $\begin{array}{l}\text { Elderly } \\
\text { patients } \\
\text { (age } \geq 75 \\
\text { years) }\end{array}$ & 1443 & $\begin{array}{l}\text { ACS } \\
\text { (STEMI/NSTEMI) } \\
\text { undergoing PCl }\end{array}$ & $\begin{array}{l}\text { Prasugrel } \\
60 / 5 \mathrm{mg} \\
(713)\end{array}$ & $\begin{array}{l}\text { clopidogrel } \\
300- \\
600 / 75 \\
\mathrm{mg}(730)\end{array}$ & Yes & Yes & 12 & 40. \\
\hline $\begin{array}{l}\text { Kitano } \\
(2019) \\
{[30]}\end{array}$ & RCT & Japan & $\begin{array}{l}\text { Asian } \\
\text { (Japanese } \\
\text { patients) }\end{array}$ & 78 & ACS undergoing $\mathrm{PCl}$ & $\begin{array}{l}\text { prasugrel } \\
20 / 3.75 \mathrm{mg} \\
(39)\end{array}$ & $\begin{array}{l}\text { clopidogrel } \\
300 / 75 \\
\mathrm{mg}(39)\end{array}$ & Yes & No & 8 & 18. \\
\hline $\begin{array}{l}\text { Akita } \\
(2020) \\
{[12]}\end{array}$ & Cohort & Japan & $\begin{array}{l}\text { Asian } \\
\text { (Japanese } \\
\text { patients) }\end{array}$ & 24032 & ACS undergoing $\mathrm{PCl}$ & $\begin{array}{l}\text { prasugrel } \\
20 / 3.75 \mathrm{mg} \\
(12016)\end{array}$ & $\begin{array}{l}\text { clopidogrel } \\
300 / 75 \\
\mathrm{mg} \\
(12016)\end{array}$ & No & Yes & $\begin{array}{l}\text { In- } \\
\text { hospital }\end{array}$ & 25. \\
\hline $\begin{array}{l}\text { Koyabu } \\
(2019) \\
{[32]}\end{array}$ & Cohort & Japan & $\begin{array}{l}\text { Asian } \\
\text { (Japanese } \\
\text { patients) }\end{array}$ & 500 & $\begin{array}{l}\text { CAD (CAD and ACS) } \\
\text { undergoing PCI }\end{array}$ & $\begin{array}{l}\text { prasugrel } \\
20 / 3.75 \mathrm{mg} \\
(250)\end{array}$ & $\begin{array}{l}\text { clopidogrel } \\
300 / 75 \\
\mathrm{mg}(250)\end{array}$ & Yes & Yes & 12 & 79. \\
\hline $\begin{array}{l}\text { Ohya } \\
\text { (2018) } \\
{[33]}\end{array}$ & Cohort & Japan & $\begin{array}{l}\text { Asian } \\
\text { (Japanese } \\
\text { patients) }\end{array}$ & 992 & ACS undergoing $\mathrm{PCl}$ & $\begin{array}{l}\text { prasugrel } \\
20 / 3.75 \mathrm{mg} \\
(487)\end{array}$ & $\begin{array}{l}\text { clopidogrel } \\
\text { NA/75 mg } \\
(192)\end{array}$ & Yes & Yes & 17 & 17. \\
\hline $\begin{array}{l}\text { Shoji } \\
(2020) \\
{[13]}\end{array}$ & Cohort & Japan & $\begin{array}{l}\text { Asian } \\
\text { (Japanese } \\
\text { patients) }\end{array}$ & 1802 & ACS undergoing $\mathrm{PCl}$ & $\begin{array}{l}\text { prasugrel } \\
20 / 3.75 \mathrm{mg} \\
(901)\end{array}$ & $\begin{array}{l}\text { clopidogrel } \\
300 / 75 \\
\mathrm{mg}(901)\end{array}$ & Yes & Yes & $\begin{array}{l}\text { In- } \\
\text { hospital }\end{array}$ & 24. \\
\hline $\begin{array}{l}\text { Tokimasa } \\
(2019) \\
{[34]}\end{array}$ & Cohort & Japan & $\begin{array}{l}\text { Asian } \\
\text { (Japanese } \\
\text { patients) }\end{array}$ & 1031 & $\mathrm{CAD}$ undergoing $\mathrm{PCl}$ & $\begin{array}{l}\text { prasugrel } \\
20 / 3.75 \mathrm{mg} \\
(412)\end{array}$ & $\begin{array}{l}\text { clopidogrel } \\
300 / 75 \\
\mathrm{mg}(619)\end{array}$ & Yes & Yes & 6 & 23. \\
\hline $\begin{array}{l}\text { Yasuda } \\
(2019) \\
{[35]}\end{array}$ & Cohort & Japan & $\begin{array}{l}\text { Asian } \\
\text { (Japanese } \\
\text { patients) }\end{array}$ & 3069 & $\begin{array}{l}\text { ACS (STEMI or } \\
\text { NSTEMI) undergoing } \\
\text { PCI }\end{array}$ & $\begin{array}{l}\text { prasugrel } \\
20 / 3.75 \mathrm{mg} \\
(2607)\end{array}$ & $\begin{array}{l}\text { clopidogrel } \\
300 / 75 \\
\mathrm{mg}(462)\end{array}$ & Yes & Yes & 12 & 23. \\
\hline
\end{tabular}

Risk of bias

The risk of bias in five RCTs (83.3\%) was rated as low risk [10, 11, 28, 29, 31]. We judged the risk of bias as high in one RCT (16.7\%) due to inadequate information about allocation concealment in the randomization process [30]. The risk of bias in three observational studies (50.0\%) was considered moderate 
$[12,13,35]$, and the other three studies (50.0\%) were considered to have serious risk of bias due to the existence of possible confounds (Figure S1) [32-34],

MACE

MACE was reported in six RCTs $(n=6020)$ [10, 11, 28-31], and five observational studies $(n=7081)[13,32-35]$. There was no difference in the risk of MACE between patients receiving low-dose prasugrel and patients receiving clopidogrel (RR $1.02,95 \% \mathrm{Cl} 0.91$ to 1.14 ; Fig. 2$)$ with low heterogeneity $\left(I^{2}=46.7 \%\right)$. Treating study design as a factor in the model yielded no significant interaction with medication (RCTs: RR $0.98,95 \% \mathrm{Cl} 0.87$ to $1.11 ; \mathrm{I}^{2}=7.8 \%$ ); observational studies: RR $1.19,95 \% \mathrm{Cl} 0.93$ to $\left.1.53 ; \mathrm{I}^{2}=65.1 \%\right) ; \mathrm{P}=0.171$ for interaction). The null result did not change when studies at serious risk of bias were excluded (RR $1.01,95 \% \mathrm{Cl} 0.91$ to $1.14 ; \mathrm{I}^{2}=12.2 \% ; n=10,891$ ) (Figure S2). The GRADE confidence in this estimate is low. No publication bias was found on inspection of funnel plots or on Egger's regression test.

Major bleeding

Major bleeding was reported in five RCT $(n=5,919)[10,11,28,29,31]$ and six observational studies $(n=31,113)[12,13,32-35]$. Overall, patients receiving low-dose prasugrel exhibited an increased risk of major bleeding relative to patients receiving clopidogrel $\left(\mathrm{RR} 1.35,95 \% \mathrm{Cl} 1.10\right.$ to $1.67 ; \mathrm{I}^{2}=61.4 \% ; \mathrm{n}=37,110$; Fig. 3). Separate analysis of observational and RCT studies yielded an increased risk of major bleeding for patients receiving prasugrel in observational studies (RR $1.57,95 \% \mathrm{Cl} 1.23$ to $2.01 ; \mathrm{I}^{2}=66.3$ ); however, there was no difference in the risk of major bleeding between drug groups in RCTs (RR $0.91,95 \% \mathrm{Cl}$ 0.61 to $\left.1.36 ; I^{2}=32.1 \%\right)$. To check for possible impact of bias, we repeated the main analysis with studies at serious risk of bias excluded. This analysis replicated the main finding with patients receiving prasugrel exhibiting an increased risk of major bleeding $\left(\mathrm{RR} 1.37,95 \% \mathrm{Cl} 1.08 \mathrm{to} 1.73 ; \mathrm{I}^{2}=64.3 \% ; \mathrm{n}=34,900\right)$ (Figure S3). The GRADE confidence in this estimate is low. No publication biases were found either on inspection of funnel plots or on Egger's regression test.

Minor bleeding

Minor bleeding was reported in five RCTs $(n=5,919)[10,11,28,29,31]$ and four observational studies $(n=4,012)[13,32-34]$. Overall, patients receiving lowdose prasugrel exhibited an increased risk of minor bleeding relative to patients receiving clopidogrel (RR $1.47,95 \% \mathrm{Cl} 1.09$ to $1.99 ; I^{2} 53.0 \%$ ). Separate analysis of observational and RCT studies yielded nonsignificant trends for both types of study design (Figure S4). The GRADE confidence in this estimate is low. No publication bias was found either on inspection of funnel plots or on Egger's regression test.

Additional outcomes

We found no difference between patients given low-dose prasugrel and standard-dose clopidogrel in the risk of all-cause mortality, cardiovascular death, myocardial infarction, stroke, or stent thrombosis (Figure S5-S9).

Subgroup analyses

Several subgroup analyses were conducted to examine the in different characteristics such as clinical events, aged groups, types of PCl, study country (Table S4). Overall, these subgroups analyses in different characteristics did not change the findings of the main analysis. However, when we separate analyses according to time to measurement outcome, low-dose prasugrel was significant increased risk of major bleeding in short-term (RR $1.97,95 \% \mathrm{Cl} 1.43$ to $2.71 ; l^{2}$ $=59.6 \%$ ) with trended to increase long-term major bleeding (RR $1.14,95 \% \mathrm{Cl} 0.78$ to $1.67 ; \mathrm{I}^{2}=61.5 \%$ ) (Figure S10). No publication biases were found either on inspection of funnel plots or on Egger's regression test in all analyses (Figure S11).

\section{Discussion}

This is the first systematic review and meta-analysis that provides a summary of efficacy and safety of low-dose prasugrel compared to the standard dose of clopidogrel in patients with ACS or patients undergoing PCI. The main findings were as follows: (1) a meta-analysis of RCTs shows that low-dose prasugrel yields similar benefits and risks as the standard dose of clopidogrel as measured by the occurrence of MACE, all-cause mortality, MI, stroke, stent thrombosis, and bleeding; however (2) a meta-analysis of observational studies revealed that the use of low-dose prasugrel was associated with a higher risk of bleeding events compared with clopidogrel, and (3) no higher risk of MACE endpoint events. These findings suggest that low-dose prasugrel offers no benefit relative to clopidogrel in preventing MACE outcomes, but it may be associated with a higher risk of bleeding.

It is well established that DAPT with aspirin and potent P2Y12 inhibitor reduces the risk of major ischemic events significantly in ACS patients undergoing PCI $[2,36,37]$. Previous research has demonstrated that the standard-dose of prasugrel significantly reduces the composite rate of death, MI, and stroke compared with clopidogrel $[7,38]$. In addition, the ISAR-REACT 5 trial showed that prasugrel was superior to ticagrelor in reducing the composite end point of death, MI, and stroke at 1 year in patients with ACS who were scheduled to undergo PCI [36]. However, prasugrel leads to an increased likelihood of major bleeding [3840]. Because of this increased risk of bleeding, the use of standard-dose prasugrel for elderly and low-body weight patients yields no net clinical benefit over standard treatments [1, 2]. In addition, people of Asian heritage exhibit increased rates of bleeding when treated with prasugrel [8, 9]. The higher risk in Asian populations may be due to differences in average body weight, thrombogenicity, or platelet P2Y12 receptor sensitivity [41]. Hence, protocols for the use of prasugrel have adopted lower recommended doses for patients with ACS, particularly in East Asian populations [42]. A large RCT in Japanese patients contributed to these recommendations with the finding that low-dose prasugrel and clopidogrel have similar efficacy and safety profiles [11].

In the present meta-analysis, we examined data collected from patients with ACS or patients undergoing PCI. We found no difference in MACE between patients treated with low-dose prasugrel and patients treated with clopidogrel. This suggests that the advantage in clinical efficacy of prasugrel over clopidogrel is lost when the dose is lowered. However, patients treated with prasugrel still exhibited a higher incidence of major bleeding events. This is

Page 5/11 
generally in agreement with the conclusions drawn in the 12 studies reviewed here. With one exception, all studies used in this analysis reported that prasugrel was associated with either an increase in major bleeding or no effect on major bleeding, and none of the studies used in this analysis reported improvements in the prevalence of MACE outcome events.

As mentioned above, the major motivation to use low-dose as opposed to standard-dose prasugrel has been the need to minimize bleeding risk. This has been a particularly important consideration for Asian patients, who are at higher risk of major bleeding when being treated for ACS or undergoing PCI [43, 44]. Indeed, 10 of the 12 studies we analyzed were done in Japan. Thus, our results suggest that even at a low dose, prasugrel carries an increased risk of bleeding in Japanese patients. It remains for future research to determine whether these effects are similar in other populations.

One confounding issue is that the Japanese protocol for prasugrel use may be different from in other countries. In Japan, most, if not all, P2Y12 inhibitors (low-dose prasugrel or clopidogrel) are administered at the time of diagnosis of ACS before confirmation of the coronary anatomy [13]. This is contrary to ESC guidelines, and likely to be atypical in most locations [3]. One reason for this difference in policy is that some studies in Japan have found advantages for early administration. For example, a recent study in Japan compared prasugrel administration at the time of initial diagnosis to administration after angiography. Patients receiving early administration of prasugrel exhibited reduced rates of in-stent thrombus and plaque protrusion. What's more, these benefits were not associated with any difference in the rate of bleeding [45]. By contrast, recent studies in other countries have failed to find any benefit for pretreatment in ACS patients, and have instead found that patients receiving early administration of prasugrel exhibited a substantially higher bleeding risk than patients receiving post-angiography prasugrel $[46,47]$. Consideration of the timing of prasugrel administration was beyond the scope of the present metaanalysis. However, the fact that Japanese protocols often indicate early prasugrel administration and the majority of the studies considered here were executed in Japan may be a confounding factor. It may be that more careful consideration of the timing of prasugrel administration could mitigate the bleeding risk reported here.

Another confound in our analysis was that patients in observational studies exhibited an increased risk of bleeding when taking low-dose prasugrel, but those in RCTs did not. It is not clear why this would be, but one issue may be that RCTs may be hesitant to include patients with certain contraindications. How these and other-potentially unmeasured-differences in patient populations may have impacted results is unclear. In general, patients with ACS and undergoing PCI are not very robust, and the observational studies reviewed here may provide more accurate real-world validity than RCTs.

A final confound was that some analyses had high heterogeneity. We noted statistical heterogeneity across the studies in terms of the various study populations, endpoints used and the duration of studies. Some heterogeneity is expected to be reported in meta-analyses of real-world evidence, and complete uniformity can show consistency in bias rather than consistency in real effects. We therefore did a random-effects meta-analysis and several subgroup analyses to explore this heterogeneity, with results in all subgroups that supported the overall conclusions of the study. Relatedly, certain subgroup analyses involved a limited number of patients and should be interpreted with caution.

In general, more studies are necessary to evaluate which risk factors for bleeding are most important for prescribing cardiologists to consider in order to avoid bleeding events. It is possible that prasugrel may be advantageous in patients with cytochrome P450 (CYP) 2 C19 poor metabolizer phenotype [48], high platelet reactivity [49], or predisposition towards higher platelet reactivity [50]. A large-scale clinical trial to identify factors which may identify patients who could benefit from the use of prasugrel is warranted.

\section{Conclusions}

This is the most comprehensive systematic review to date examining the efficacy and safety of low-dose prasugrel for patients with ACS or undergoing PCI. The use of low-dose prasugrel offers no efficacy improvement relative to clopidogrel, but low-dose prasugrel does carry an increased risk of bleeding complications. These data suggest that prasugrel, even at low doses, should not be used with typical ACS patients or patients undergoing PCI. Many of the studies on which this analysis was based were conducted in Japan with relatively elderly patients. It remains a subject for future research to determine whether prasugrel can be used safely in other populations. Of particular interest would be observational studies replicating the inclusion and exclusion criteria of the Japanese studies reviewed here in other populations.

\section{Declarations}

\section{Acknowledgements}

We are grateful to Adam Joseph Osman Dede (Research specialist, School of Pharmaceutical Sciences, University of Phayao) for proofreading and English language review.

\section{Author's Contributions}

Yuttana Wongsalap: design, data collection, analysis, interpretation, writing the manuscript, critical revision, and final approval

Supakorn Ungsriwong: data collection

Wanalee Kumtepm: data collection

Surasak Saokaew: data collection, critical revision, and final approval

Vichai Senthong: critical revision, and final approval 
Kirati Kengkla: design, data collection, analysis, interpretation, writing the manuscript, critical revision, and final approval

\section{Funding}

The study was partially funded by a grant from University of Phayao under Unit of Excellence on Clinical Outcomes Research and IntegratioN (UNICORN) [grant number: FF64-UoE003].

\section{Data Availability}

The authors confirm that the data supporting the findings of this study are available within the article and its supplementary materials.

\section{Compliance with Ethical Standards}

\section{Ethical approval}

This article does not contain any studies with human participants or animals performed by any of the authors.

\section{Conflict of Interest}

The authors declare that they have no conflict of interest.

\section{References}

1. Levine GN, Bates ER, Bittl JA, Brindis RG, Fihn SD, Fleisher LA, et al. 2016 ACC/AHA Guideline Focused Update on Duration of Dual Antiplatelet Therapy in Patients With Coronary Artery Disease: A Report of the American College of Cardiology/American Heart Association Task Force on Clinical Practice Guidelines. J Am Coll Cardiol. 2016;68(10):1082-115. doi:10.1016/j.jacc.2016.03.513.

2. Valgimigli M, Bueno H, Byrne RA, Collet JP, Costa F, Jeppsson A, et al. 2017 ESC focused update on dual antiplatelet therapy in coronary artery disease developed in collaboration with EACTS: The Task Force for dual antiplatelet therapy in coronary artery disease of the European Society of Cardiology (ESC) and of the European Association for Cardio-Thoracic Surgery (EACTS). Eur Heart J. 2018;39(3):213-60. doi:10.1093/eurheartj/ehx419.

3. Collet JP, Thiele H, Barbato E, Barthélémy O, Bauersachs J, Bhatt DL, et al. 2020 ESC Guidelines for the management of acute coronary syndromes in patients presenting without persistent ST-segment elevation. Eur Heart J. 2020 Aug 29:ehaa575. doi:10.1093/eurheartj/ehaa575.

4. Aradi D, Storey RF, Komócsi A, Trenk D, Gulba D, Kiss RG, et al. Expert position paper on the role of platelet function testing in patients undergoing percutaneous coronary intervention. Eur Heart J. 2014;35(4):209-15. doi:10.1093/eurheartj/eht375.

5. Savi P, Herbert JM. Clopidogrel and ticlopidine: P2Y12 adenosine diphosphate-receptor antagonists for the prevention of atherothrombosis. Semin Thromb Hemost. 2005;31(2):174-83. doi:10.1055/s-2005-869523.

6. Michelson AD, Frelinger AL 3rd, Braunwald E, Downey WE, Angiolillo DJ, Xenopoulos NP, et al. Pharmacodynamic assessment of platelet inhibition by prasugrel vs. clopidogrel in the TRITON-TIMI 38 trial. Eur Heart J. 2009;30(14):1753-63. doi:10.1093/eurheartj/ehp159.

7. Wiviott SD, Braunwald E, McCabe CH, Montalescot G, Ruzyllo W, Gottlieb S, et al. Prasugrel versus clopidogrel in patients with acute coronary syndromes. N Engl J Med. 2007;357(20):2001-15. doi:10.1056/NEJMoa0706482.

8. Park KH, Jeong MH, Kim HK, Ahn TH, Seung KB, Oh DJ, et al. Comparison of prasugrel versus clopidogrel in Korean patients with acute myocardial infarction undergoing successful revascularization. J Cardiol. 2018;71(1):36-43. doi:10.1016/j.jjcc.2017.05.003.

9. Yun JE, Kim YJ, Park JJ, Kim S, Park K, Cho MS, et al. Safety and Effectiveness of Contemporary P2Y(12) Inhibitors in an East Asian Population With Acute Coronary Syndrome: A Nationwide Population-Based Cohort Study. J Am Heart Assoc. 2019;8(14):e012078. doi:10.1161/jaha.119.012078.

10. Roe MT, Goodman SG, Ohman EM, Stevens SR, Hochman JS, Gottlieb S, et al. Elderly patients with acute coronary syndromes managed without revascularization: insights into the safety of long-term dual antiplatelet therapy with reduced-dose prasugrel versus standard-dose clopidogrel. Circulation. 2013;128(8):823-33. doi:10.1161/circulationaha.113.002303.

11. Saito S, Isshiki T, Kimura T, Ogawa H, Yokoi H, Nanto S, et al. Efficacy and safety of adjusted-dose prasugrel compared with clopidogrel in Japanese patients with acute coronary syndrome: the PRASFIT-ACS study. Circ J. 2014;78(7):1684-92. doi:10.1253/circj.cj-13-1482.

12. Akita K, Inohara T, Yamaji K, Kohsaka S, Numasawa Y, Ishii H, et al. Impact of reduced-dose prasugrel vs. standard-dose clopidogrel on in-hospital outcomes of percutaneous coronary intervention in 62737 patients with acute coronary syndromes: a nationwide registry study in Japan. Eur Heart $J$ Cardiovasc Pharmacother. 2020;6(4):231-8. doi:10.1093/ehjcvp/pvz056.

13. Shoji S, Sawano M, Sandhu AT, Heidenreich PA, Shiraishi Y, Ikemura N, et al. Ischemic and Bleeding Events Among Patients With Acute Coronary Syndrome Associated With Low-Dose Prasugrel vs Standard-Dose Clopidogrel Treatment. JAMA Netw Open. 2020;3(4):e202004. doi:10.1001/jamanetworkopen.2020.2004.

14. Liberati A, Altman DG, Tetzlaff J, Mulrow C, Gotzsche PC, loannidis JP, et al. The PRISMA statement for reporting systematic reviews and meta-analyses of studies that evaluate health care interventions: explanation and elaboration. PLoS Med. 2009;6(7):e1000100. doi:10.1371/journal.pmed.1000100.

15. Stroup DF, Berlin JA, Morton SC, Olkin I, Williamson GD, Rennie D, et al. Meta-analysis of observational studies in epidemiology: a proposal for reporting. Meta-analysis Of Observational Studies in Epidemiology (MOOSE) group. JAMA. 2000;283(15):2008-12. doi:10.1001/jama.283.15.2008.

16. Wongsalap Y, Kengkla K, Saokaew S. Efficacy and safety of low-dose prasugrel in patients with coronary artery diseases: a systematic review and metaanalysis. PROSPERO 2020 CRD42020188261.

17. The Thrombolysis in Myocardial. Infarction (TIMI) trial. Phase I findings. N Engl J Med. 1985;312(14):932-6. doi:10.1056/nejm198504043121437.

Page $7 / 11$ 
18. Mehran R, Rao SV, Bhatt DL, Gibson CM, Caixeta A, Eikelboom J, et al. Standardized bleeding definitions for cardiovascular clinical trials: a consensus report from the Bleeding Academic Research Consortium. Circulation. 2011;123(23):2736-47. doi:10.1161/circulationaha.110.009449.

19. Sterne JAC, Savović J, Page MJ, Elbers RG, Blencowe NS, Boutron I, et al. RoB 2: a revised tool for assessing risk of bias in randomised trials. BMJ. 2019;366:I4898. doi:10.1136/bmj.14898.

20. Sterne JA, Hernan MA, Reeves BC, Savovic J, Berkman ND, Viswanathan M, et al. ROBINS-I: a tool for assessing risk of bias in non-randomised studies of interventions. BMJ. 2016;355:i4919. doi:10.1136/bmj.i4919.

21. Higgins JPT, Thomas J, Chandler J, Cumpston M, Li TPM, Welch VA. Cochrane Handbook for Systematic Reviews of Interventions version 6.1 (updated September 2020). 2020.

22. DerSimonian R, Laird N. Meta-analysis in clinical trials. Controlled clinical trials. 1986;7(3):177-88.

23. Borenstein M, Hedges LV, Higgins JP, Rothstein HR. A basic introduction to fixed-effect and random-effects models for meta-analysis. Res Synth Methods. 2010;1(2):97-111. doi:10.1002/jrsm.12.

24. Shor E, Roelfs D, Vang ZM. The "Hispanic mortality paradox" revisited: Meta-analysis and meta-regression of life-course differentials in Latin American and Caribbean immigrants' mortality. Soc Sci Med. 2017;186:20-33. doi:10.1016/j.socscimed.2017.05.049.

25. Sterne JA, Sutton AJ, loannidis JP, Terrin N, Jones DR, Lau J, et al. Recommendations for examining and interpreting funnel plot asymmetry in metaanalyses of randomised controlled trials. BMJ. 2011;343:d4002. doi:10.1136/bmj.d4002.

26. Guyatt G, Oxman AD, AkI EA, Kunz R, Vist G, Brozek J, et al. GRADE guidelines: 1. Introduction-GRADE evidence profiles and summary of findings tables. J Clin Epidemiol. 2011;64(4):383-94. doi:10.1016/j.jclinepi.2010.04.026.

27. Puhan MA, Schünemann HJ, Murad MH, Li T, Brignardello-Petersen R, Singh JA, et al. A GRADE Working Group approach for rating the quality of treatment effect estimates from network meta-analysis. BMJ. 2014;349:g5630. doi:10.1136/bmj.g5630.

28. Isshiki T, Kimura T, Ogawa H, Yokoi H, Nanto S, Takayama M, et al. Prasugrel, a third-generation P2Y12 receptor antagonist, in patients with coronary artery disease undergoing elective percutaneous coronary intervention. Circ J. 2014;78(12):2926-34. doi:10.1253/circj.cj-14-0266.

29. Kimura T, Isshiki T, Ogawa H, Yokoi H, Yamaguchi T, Ikeda Y. Randomized, double-blind, dose-finding, phase II study of prasugrel in japanese patients undergoing elective percutaneous coronary intervention. J Atheroscler Thromb. 2015;22(6):557-69. doi:10.5551/jat.26013.

30. Kitano D, Takayama T, Fukamachi D, Migita S, Morikawa T, Tamaki T, et al. Impact of low-dose prasugrel on platelet reactivity and cardiac dysfunction in acute coronary syndrome patients requiring primary drug-eluting stent implantation: a randomized comparative study. Catheter Cardiovasc Interv. 2019;95(1):1-9. doi:10.1002/ccd.28277.

31. Savonitto S, Ferri LA, Piatti L, Grosseto D, Piovaccari G, Morici N, et al. Comparison of reduced-dose prasugrel and standard-dose clopidogrel in elderly patients with acute coronary syndromes undergoing early percutaneous revascularization. Circulation. 2018;137(23):2435-45. doi:10.1161/circulationaha.117.032180.

32. Koyabu Y, Abe S, Sakuma M, Kanaya T, Obi S, Yoneda S, et al. Short-term safety and mid-term efficacy of prasugrel versus clopidogrel in patients undergoing percutaneous coronary intervention. Intern Med. 2019;58(16):2315-22. doi:10.2169/internalmedicine.2262-18.

33. Ohya M, Shimada T, Osakada K, Kuwayama A, Miura K, Murai R, et al. In-hospital bleeding and utility of a maintenance dose of prasugrel 2.5 mg in high bleeding risk patients with acute coronary syndrome. Circ J. 2018;82(7):1874-83. doi:10.1253/circj.CJ-18-0114.

34. Tokimasa S, Kitahara H, Nakayama T, Fujimoto Y, Shiba T, Shikama N, et al. Multicenter research of bleeding risk between prasugrel and clopidogrel in Japanese patients with coronary artery disease undergoing percutaneous coronary intervention. Heart Vessels. 2019;34(10):1581-8. doi:10.1007/s00380-019-01395-0.

35. Yasuda S, Honda S, Takegami M, Nishihira K, Kojima S, Asaumi Y, et al. Contemporary antiplatelet therapy and clinical outcomes of japanese patients with acute myocardial infarction - results from the prospective Japan acute myocardial infarction registry (JAMIR). Circ J. 2019;83(8):1633-43. doi:10.1253/circj.CJ-19-0145.

36. Schüpke S, Neumann FJ, Menichelli M, Mayer K, Bernlochner I, Wöhrle J, et al. Ticagrelor or Prasugrel in Patients with Acute Coronary Syndromes. N Engl J Med. 2019;381(16):1524-34. doi:10.1056/NEJMoa1908973.

37. Wallentin L, Becker RC, Budaj A, Cannon CP, Emanuelsson H, Held C, et al. Ticagrelor versus clopidogrel in patients with acute coronary syndromes. N Engl J Med. 2009;361(11):1045-57. doi:10.1056/NEJMoa0904327.

38. Chen HB, Zhang XL, Liang HB, Liu XW, Zhang XY, Huang BY, et al. Meta-Analysis of Randomized Controlled Trials Comparing Risk of Major Adverse Cardiac Events and Bleeding in Patients With Prasugrel Versus Clopidogrel. Am J Cardiol. 2015;116(3):384-92. doi:10.1016/j.amjcard.2015.04.054.

39. Bavishi C, Panwar S, Messerli FH, Bangalore S. Meta-Analysis of Comparison of the Newer Oral P2Y12 Inhibitors (Prasugrel or Ticagrelor) to Clopidogrel in Patients With Non-ST-Elevation Acute Coronary Syndrome. Am J Cardiol. 2015;116(5):809-17. doi:10.1016/j.amjcard.2015.05.058.

40. Bellemain-Appaix A, Brieger D, Beygui F, Silvain J, Pena A, Cayla G, et al. New P2Y12 inhibitors versus clopidogrel in percutaneous coronary intervention: a meta-analysis. J Am Coll Cardiol. 2010;56(19):1542-51. doi:10.1016/j.jacc.2010.07.012.

41. Levine GN, Jeong YH, Goto S, Anderson JL, Huo Y, Mega JL, et al. Expert consensus document: World Heart Federation expert consensus statement on antiplatelet therapy in East Asian patients with ACS or undergoing PCI. Nat Rev Cardiol. 2014;11(10):597-606. doi:10.1038/nrcardio.2014.104.

42. Kimura K, Kimura T, Ishihara M, Nakagawa Y, Nakao K, Miyauchi K, et al. JCS 2018 Guideline on Diagnosis and Treatment of Acute Coronary Syndrome. Circ J. 2019;83(5):1085-196. doi:10.1253/circj.CJ-19-0133.

43. Kohsaka S, Miyata H, Ueda I, Masoudi FA, Peterson ED, Maekawa Y, et al. An international comparison of patients undergoing percutaneous coronary intervention: A collaborative study of the National Cardiovascular Data Registry (NCDR) and Japan Cardiovascular Database-Keio interhospital Cardiovascular Studies (JCD-KiCS). Am Heart J. 2015;170(6):1077-85. doi:10.1016/j.ahj.2015.09.017.

Page $8 / 11$ 
44. Wang TY, Chen AY, Roe MT, Alexander KP, Newby LK, Smith SC Jr, et al. Comparison of baseline characteristics, treatment patterns, and in-hospital outcomes of Asian versus non-Asian white Americans with non-ST-segment elevation acute coronary syndromes from the CRUSADE quality improvement initiative. Am J Cardiol. 2007;100(3):391-6. doi:10.1016/j.amjcard.2007.03.035.

45. Katayama Y, Kubo T, Ino Y, Kameyama T, Matsuo Y, Kitabata H, et al. The relationship between timing of prasugrel pretreatment and in-stent thrombus immediately after percutaneous coronary intervention for acute coronary syndrome: an optical coherence tomography study. Heart Vessels. 2018;33(10):1159-67. doi:10.1007/s00380-018-1167-8.

46. Dworeck C, Redfors B, Angerås O, Haraldsson I, Odenstedt J, loanes D, et al. Association of Pretreatment With P2Y12 Receptor Antagonists Preceding Percutaneous Coronary Intervention in Non-ST-Segment Elevation Acute Coronary Syndromes With Outcomes. JAMA Netw Open. 2020;3(10):e2018735. doi:10.1001/jamanetworkopen.2020.18735.

47. Montalescot G, Bolognese L, Dudek D, Goldstein P, Hamm C, Tanguay JF, et al. Pretreatment with prasugrel in non-ST-segment elevation acute coronary syndromes. N Engl J Med. 2013;369(11):999-1010. doi:10.1056/NEJMoa1308075.

48. Brown SA, Pereira N. Pharmacogenomic Impact of CYP2C19 Variation on Clopidogrel Therapy in Precision Cardiovascular Medicine. J Pers Med. 2018;8(1). doi:10.3390/jpm8010008.

49. Geisler T, Booth J, Tavlaki E, Karathanos A, Müller K, Droppa M, et al. High Platelet Reactivity in Patients with Acute Coronary Syndromes Undergoing Percutaneous Coronary Intervention: Randomised Controlled Trial Comparing Prasugrel and Clopidogrel. PLoS One. 2015;10(8):e0135037. doi:10.1371/journal.pone.0135037.

50. Johnston LR, Larsen PD, La Flamme AC, Michel JM, Simmonds MB, Harding SA. Suboptimal response to clopidogrel and the effect of prasugrel in acute coronary syndromes. Int J Cardiol. 2013;167(3):995-9. doi:10.1016/j.ijcard.2012.03.080.

\section{Figures}

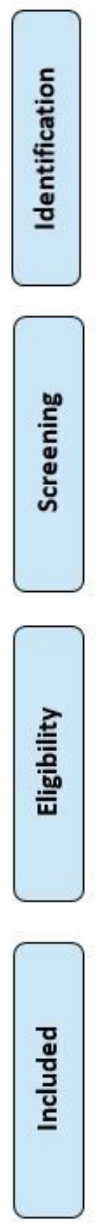

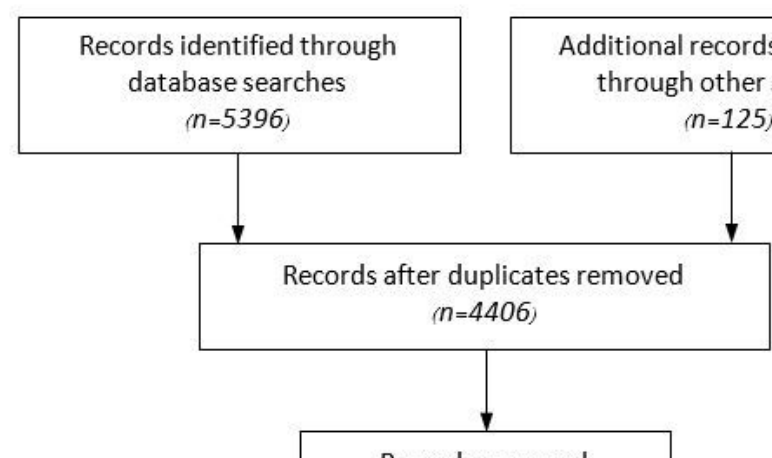
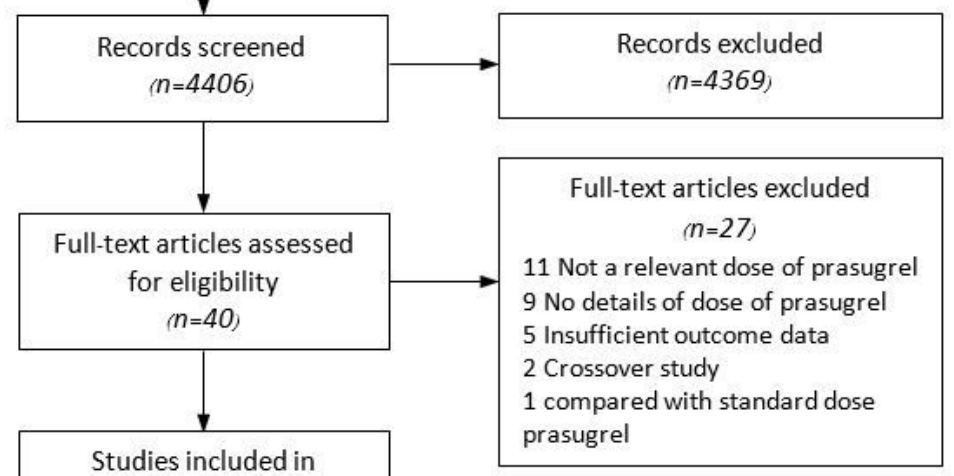

qualitative synthesis $(n=12)$

Studies included in meta-analysis $(n=12$

\section{Figure 1}

Flow diagram and references of included studies 


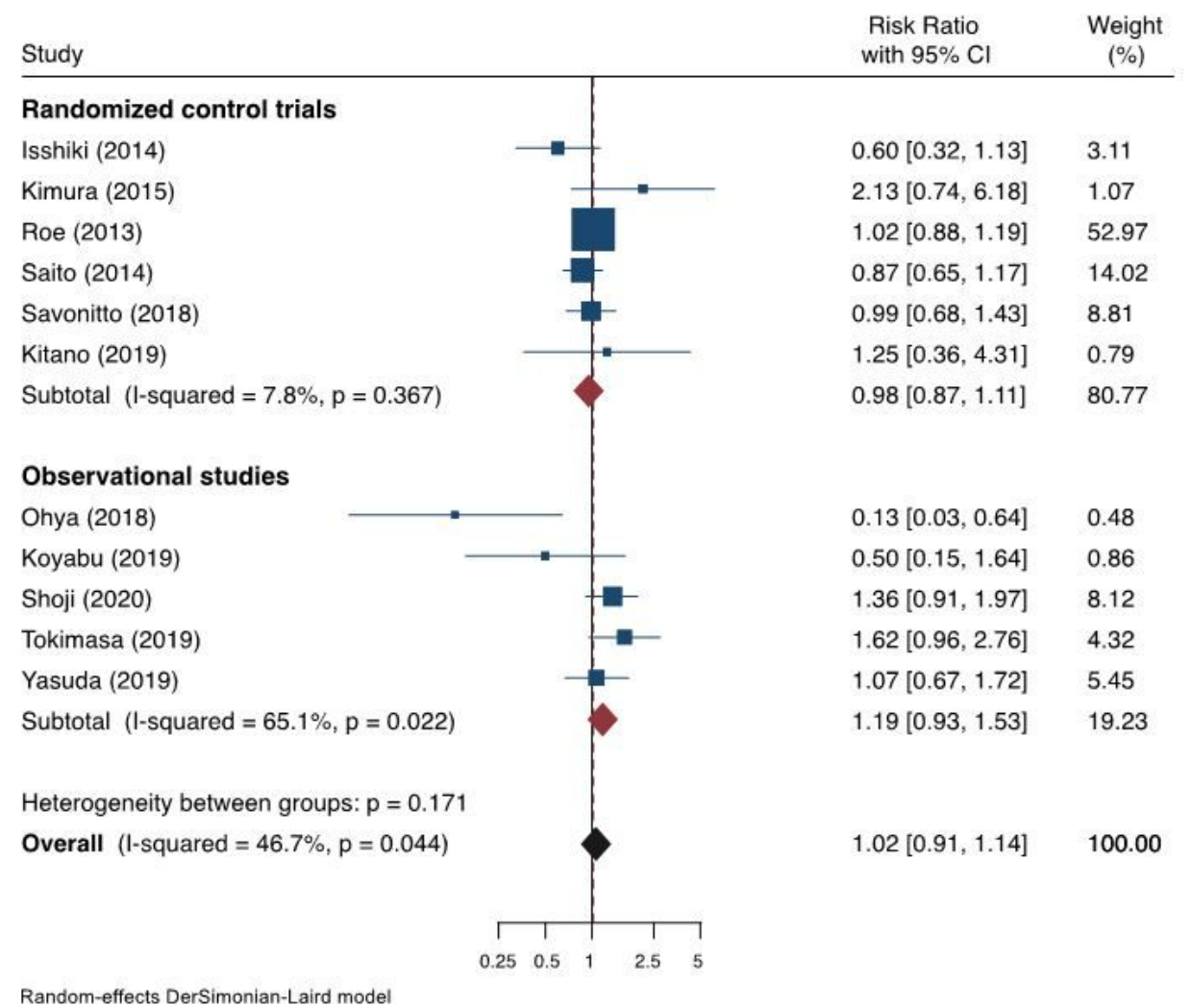

Figure 2

Major adverse cardiac events (MACE) outcome observed with low dose prasugrel versus standard dose clopidogrel

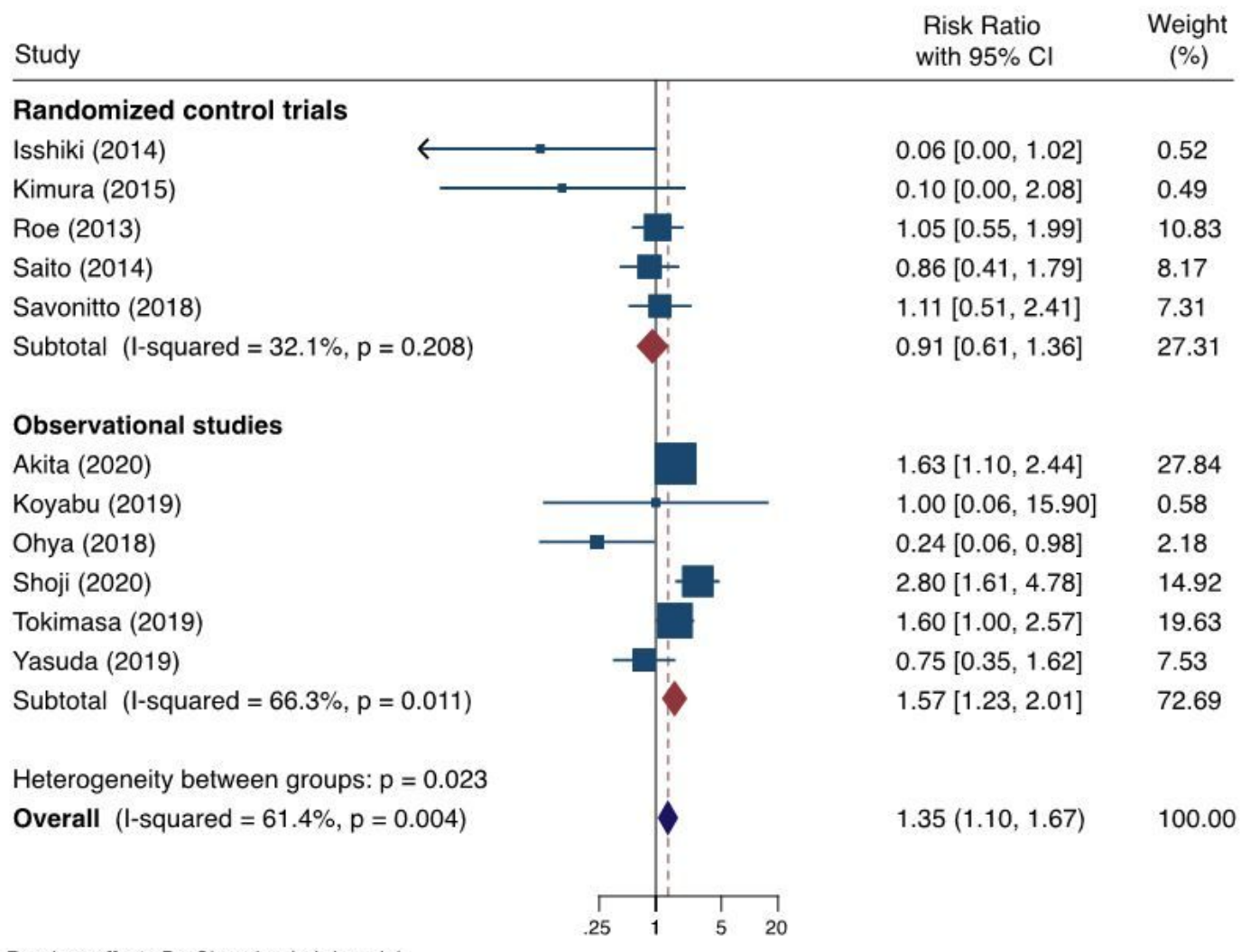


Figure 3

Major bleeding outcome observed with low dose prasugrel versus standard dose clopidogrel

\section{Supplementary Files}

This is a list of supplementary files associated with this preprint. Click to download.

- SupplementaryappendixCardiovasc.pdf 